\title{
ホウ素含有アパタイト中のホウ酸基の構造
}

\author{
伊藤敦夫・青木秀希* ·赤尾勝* · 三浦直樹* · 大塚良平 - 堤 貞夫** \\ 早稲田大学理工学部資源工学科, 160 東京都新宿区大久保 3-4-1 \\ * 東京医科歯科大学医用器材研究所, 101 東京都千代田区神田駿河台 2-3-10 \\ ** 早稲田大学教育学部理学科地学専修, 160 東京都新宿区西早稲田 1-6-1
}

\section{Structure of Borate Groups in Boron-Containing Apatite}

\author{
Atsuo ITO, Hideki AOKI*, Masaru AKAO*, Naoki MIURA*, Ryohei OTSUKA and Sadao TSUTSUMI** \\ Department of Mineral Industry, School of Science and Engineering, Waseda University, \\ 3-4-1, Ookubo, Shinjuku-ku, Tokyo 160 \\ * Division of Inorganic Materials, Institute for Medical and Dental Engineering, Tokyo Medical and Dental University, \\ 2-3-10, Kanda Surugadai, Chiyoda-ku, Tokyo 101 \\ ** Institute of Earth Science, School of Education, Waseda University, 1-6-1, Nishiwaseda, Shinjuku-ku, Tokyo 160
}

${ }^{11} \mathrm{~B}$ - and ${ }^{10} \mathrm{~B}$-containing apatites were prepared from the system $\mathrm{CaO}-\mathrm{P}_{2} \mathrm{O}_{5}-\mathrm{B}_{2} \mathrm{O}_{3}$ at $1000^{\circ} \mathrm{C}$. The structure of borate groups was investigated by infrared spectroscopy based on isotopic frequency shifts. The boron-containing apatite has both $\mathrm{BO}_{2}$ and $\mathrm{BO}_{3}$ groups, but it does not contain $\mathrm{BO}_{4}$ groups. The $\mathrm{BO}_{3}$ groups occupy $\mathrm{PO}_{4}$ site of the apatite structure.

[Received December 2, 1987; Accepted February 23, 1988]

Key-words : Boron-containing apatite, Infrared spectroscopy, Isotopic frequency shifts, $\mathrm{BO}_{2}$ groups, $\mathrm{BO}_{3}$ groups

\section{1. はじめに}

$\mathrm{CaO}-\mathrm{P}_{2} \mathrm{O}_{5}-\mathrm{B}_{2} \mathrm{O}_{3}$ 系からホウ素含有アパタイト（以下 $\mathrm{BAP}$ と略) が合成されることが報告されている. Ramamoorthy とRockett (1974) ${ }^{1)}$ は BAP を $\mathrm{Ca}_{10}$ $\left(\mathrm{PO}_{4}\right)_{5} \mathrm{BO}_{4}-\mathrm{Ca}_{10-7 \delta}\left(\mathrm{PO}_{4}\right)_{6-4 \sigma} \mathrm{O}_{1-\delta}(\delta \fallingdotseq 0.77)$ 系の固溶 体であると考え，ホウ酸基は $\mathrm{BO}_{4}$ 基が $\mathrm{PO}_{4}$ 基を置換す ると考えた。一方 Calvoら $(1974)^{2)}$ はアパタイト型化 合物 $\mathrm{Ca}_{9+y} \mathrm{Na}_{x}\left(\mathrm{PO}_{4}\right)_{6} \mathrm{~B}_{x+2 y} \mathrm{O}_{2}(9+y+x<10, x+2 y<1)$ の $\mathrm{X}$ 線結晶構造解析を行って, $\mathrm{B}$ が $\mathrm{BO}_{2}$ 基として $\mathrm{OH}$ カラムに存在することを示した。伊藤ら $(1987)^{3)}$ は $\mathrm{BAP}$ 単結晶の化学分析と結晶構造解析を行い, BAP の組成が $\mathrm{Ca}_{10}\left(\mathrm{PO}_{4}\right)_{5} \mathrm{BO}_{4}-\mathrm{Ca}_{9.5}\left(\mathrm{PO}_{4}\right)_{6} \mathrm{BO}_{2}$ 系固溶体とし て表せること, $\mathrm{OH}$ カラム中ではホウ酸基が $\mathrm{BO}_{2}$ 基と して存在することを示しだ3.

しかし $\mathrm{PO}_{4}$ サイトではホウ酸基が $\mathrm{BO}_{3}$ 基で存在する のか $\mathrm{BO}_{4}$ 基で存在するのかは解明されていない. 本研 究では ${ }^{10} \mathrm{~B}$ に富むホウ素含有アパタイト (以下 ${ }^{10} \mathrm{BAP}$ と略) と ${ }^{11} \mathrm{~B}$ に富むホウ素含有アパタイト (以下 ${ }^{11} \mathrm{BAP}$ と略）を合成し，赤外吸収スペクトルの同位体効果を利 用してホウ酸基の構造を調べた.

\section{2. 実験方法}

出発物質には, 水酸アパタイト $\mathrm{Ca}_{10}\left(\mathrm{PO}_{4}\right)_{6}(\mathrm{OH})_{2}$ (以 下 $\mathrm{HAP}$ と略), $\mathrm{CaO}, \mathrm{B}_{2} \mathrm{O}_{3}$ を用いた. $\mathrm{HAP}$ は湿式合 成したもので, $\mathrm{Ca} / \mathrm{P}$ モル比は 1.69 であった. $\mathrm{CaO}$ は アルカリ分析用 $\mathrm{CaCO}_{3}$ を $950^{\circ} \mathrm{C}, 3$ 時間焼成したもの
である. ${ }^{11} \mathrm{BAP}$ の合成には特級試薬の $\mathrm{B}_{2} \mathrm{O}_{3}\left({ }^{11} \mathrm{~B}:{ }^{10} \mathrm{~B}=\right.$ $80.2: 19.8 \mathrm{wt} \%)^{4)}$ を用いた。 ${ }^{10} \mathrm{BAP}$ の合成には金属 ${ }^{10} \mathrm{~B}\left({ }^{10} \mathrm{~B}\right.$ を $90 \mathrm{wt} \%$ 以上含有) を熱濃硝酸で酸化した $\mathrm{B}_{2} \mathrm{O}_{3}$ を用いた。

これらの $\mathrm{HAP}, \mathrm{CaO}, \mathrm{B}_{2} \mathrm{O}_{3}$ を $\mathrm{CaO}: \mathrm{P}_{2} \mathrm{O}_{5}: \mathrm{B}_{2} \mathrm{O}_{3}=$ $48: 28: 24 \mathrm{wt} \%$ に混合した出発物質 $1.4 \mathrm{~g}$ を $1000^{\circ} \mathrm{C}$ で 5 時間加熱した. 合成物を急冷した後, BAP ととも に生成するガラスを $5 \%$ 酢酸中で加熱, 溶解除去し, 約 $100 \mathrm{mg}$ の BAP を得た. BAP 以外の結晶相が存在しな いことを粉末 $\mathrm{X}$ 線回折法で確認した後, 赤外吸収スペ クトル測定用の試料とした. 赤外吸収スペクトルは日立 赤外分光光度計 260-50 を用い, $\mathrm{KBr}$ 錠剤法で測定した. 波数の測定精度は $4000 \sim 2000 \mathrm{~cm}^{-1}$ の範囲で土 $2 \mathrm{~cm}^{-1}$, 2000 2 $50 \mathrm{~cm}^{-1}$ の範囲で $11 \mathrm{~cm}^{-1}$ である. 波数はポリス チレン膜で校正した.

$\mathrm{B}$ は ${ }^{11} \mathrm{~B}$ のかに ${ }^{10} \mathrm{~B}$ が $19.8 \mathrm{wt} \%$ 含まれる 赤外吸収スペクトルの吸収帯が分離 (同位体ペア) する ことがあり, 帰属を行う際に障害となる.そこで, はじ めに ${ }^{11} \mathrm{BAP} と{ }^{10} \mathrm{BAP}$ の赤外吸収スペクトルを比較し て，同位体ペアの判別をした．次に Teller-Redlich の 積の法則 ${ }^{5)}$ 用いて吸収帯の帰属を決定し, $\mathrm{PO}_{4}$ サイト と $\mathrm{OH}$ カラムでのホウ酸基の構造を調べた.

$\mathrm{PO}_{4}$ サイトと $\mathrm{OH}$ カラムの結晶場対称はそれぞれ $\mathrm{C}_{1}$, $\mathrm{S}_{6}$ であるが, ホウ酸基は自由イオンの対称性を持つと 仮定して積の法則を適用した。 $\mathrm{C}_{1}$ を採用すると基準振 動がすべて一つの対称種 Aに属することになり, 積の 
法則から一つの関係式しか導けず，帰属の決定には不適 当であったからである.また $\mathrm{BO}_{2}$ 基については自由イ オン $\left(\mathrm{D}_{\infty \mathrm{h}}\right)$ として扱っても $\mathrm{S}_{6}$ の場合と同じ関係式が 導ける.

\section{3. 結 果}

図 1 に $\mathrm{HAP},{ }^{11} \mathrm{BAP},{ }^{10} \mathrm{BAP}$ の赤外吸収スペクトル を示す。 ${ }^{11} \mathrm{BAP},{ }^{10} \mathrm{BAP}$ の赤外吸収スペクトルには $\mathrm{OH}$ 基の吸収帯 $\left(3570,630,355,343 \mathrm{~cm}^{-1}\right)$ は認められな かった。代わりに 2007，1939，1312～1210，914，813

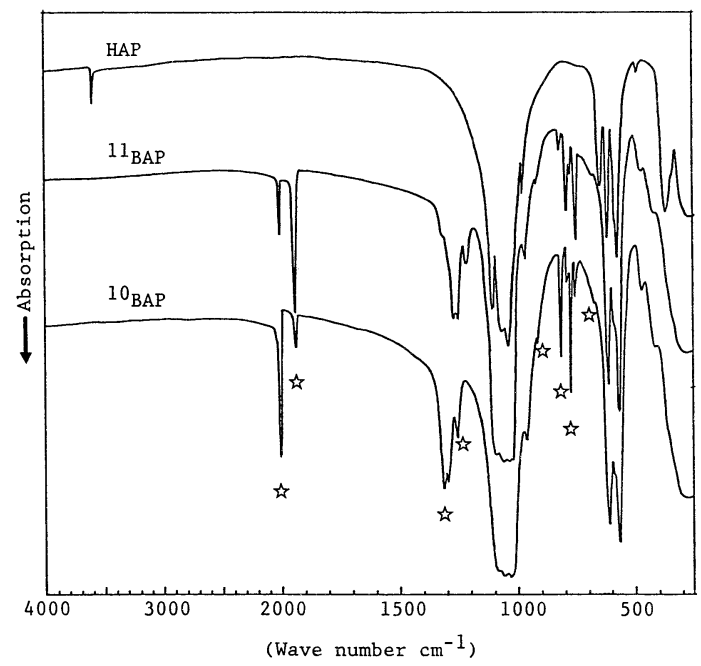

Fig. 1. Infrared spectra of HAP, ${ }^{11} \mathrm{BAP}$ and ${ }^{10} \mathrm{BAP}$ from 4000 to $250 \mathrm{~cm}^{-1}$. Stars indicate the absorption bands of borate modes.
〜 745，675〜674，414〜 413 cm-1に吸収帯が出現した. 2007 と $1939 \mathrm{~cm}^{-1}$ の吸収帯を比較すると ${ }^{1} \mathrm{BAP}$ では $1939 \mathrm{~cm}^{-1}$ の方が吸収強度が大きいのに ${ }^{10} \mathrm{BAP}$ では 2007 $\mathrm{cm}^{-1}$ の方が吸収強度が大きい，したがってこれら 2 本 の吸収帯は, $2007 \mathrm{~cm}^{-1}$ が ${ }^{10} \mathrm{~B} に, 1939 \mathrm{~cm}^{-1}$ が $^{11} \mathrm{~B}$ に起因する同位体ペアである. 同様に 1312 と $1270 \mathrm{~cm}^{-1}$, 813 と $784 \mathrm{~cm}^{-1}, 773$ と $745 \mathrm{~cm}^{-1}$ の吸収帯もそれぞれ同 位体ペアで，すべて高波数側が ${ }^{10} \mathrm{~B}$ に，低波数側が ${ }^{11} \mathrm{~B}$

Table 1. Predicted square frequency ratios according to the Teller-Redlich product rule. ${ }^{5)}$

$\nu_{\mathrm{k}}^{i}$ represents $\nu_{\mathrm{k}}$ vibrational frequency for the borate group of ${ }^{i} \mathrm{~B}$.

$m(A)$ represents the mass of atom or molecule $A$. $\mathrm{D}_{\infty \mathrm{h}}, \mathrm{D}_{3 \mathrm{~h}}$ and $\mathrm{T}_{\mathrm{d}}$ symmetries are assumed for $\mathrm{BO}_{2}, \mathrm{BO}_{3}$ and $\mathrm{BO}_{4}$ groups respectively.

$$
\begin{aligned}
& \mathrm{BO}_{2} \text { group, }\left(\mathrm{D}_{\infty \mathrm{ch}}\right) \\
& \begin{aligned}
\left(\frac{v_{2}^{1}}{v_{2}^{10}}\right)^{2}=\left(\frac{v_{3}^{1}}{v_{3}^{10}}\right)^{2} & =\frac{\mathrm{m}\left({ }^{10} \mathrm{~B}\right)}{\mathrm{m}\left({ }^{11} \mathrm{~B}\right)} \times \frac{\mathrm{m}\left({ }^{1}{ }^{1} \mathrm{BO}_{2}\right)}{\mathrm{m}\left({ }^{10}{ }^{0} \mathrm{BO}_{2}\right)} \\
& =0.931
\end{aligned} \\
& \left.\mathrm{BO}_{3} \text { group , ( } \mathrm{D}_{3 \mathrm{~h}}\right) \\
& \left(\frac{v_{1}^{11}}{v_{1}^{10}}\right)^{2}= \\
& \text { (2) } \\
& \left(\frac{v_{2}^{\frac{1}{1}}}{v_{2}^{10}}\right)^{2}=\frac{\mathrm{m}\left({ }^{10} \mathrm{~B}\right)}{\mathrm{m}\left({ }^{11} \mathrm{~B}\right)} \times \frac{\mathrm{m}\left({ }^{\left.1{ }^{1} \mathrm{BO}_{3}\right)}\right.}{\mathrm{m}\left({ }^{10} \mathrm{BO}_{3}\right)}=0.925 \\
& \left(\frac{v_{3}^{11} \cdot v_{4}^{11}}{v_{3}^{10} \cdot v_{4}^{10}}\right)^{2}=\frac{\mathrm{m}\left({ }^{10} \mathrm{~B}\right)}{\mathrm{m}\left({ }^{11} \mathrm{~B}\right)} \times\left\{\frac{\mathrm{m}\left({ }^{11} \mathrm{BO}_{3}\right)}{\mathrm{m}\left({ }^{10} \mathrm{BO}_{3}\right)}\right\}^{2}=0.941
\end{aligned}
$$

$\mathrm{BO}_{4}$ group , $\left(\mathrm{T}_{\mathrm{d}}\right)$

$$
\begin{aligned}
& \left(\frac{v_{1}^{1}}{v_{1}^{10}}\right)^{2}=\left(\frac{v_{2}^{1}{ }^{1}}{v_{2}^{10}}\right)^{2}=1 \\
& \left(\frac{v_{3}^{11} \cdot v_{4}^{11}}{v_{3}^{10} \cdot v_{4}^{10}}\right)^{2}=\frac{\mathrm{m}\left({ }^{10} \mathrm{~B}\right)}{\mathrm{m}\left({ }^{11} \mathrm{~B}\right)} \times \frac{\mathrm{m}\left({ }^{11} \mathrm{~B} \mathrm{O}_{4}\right)}{\mathrm{m}\left({ }^{10} \mathrm{BO}_{4}\right)}=0.922
\end{aligned}
$$

Table 2. Infrared frequencies $\left(\mathrm{cm}^{-1}\right)$, observed square frequency ratios and band assignments for borate modes.

* Brackets indicate isotopic pairs.

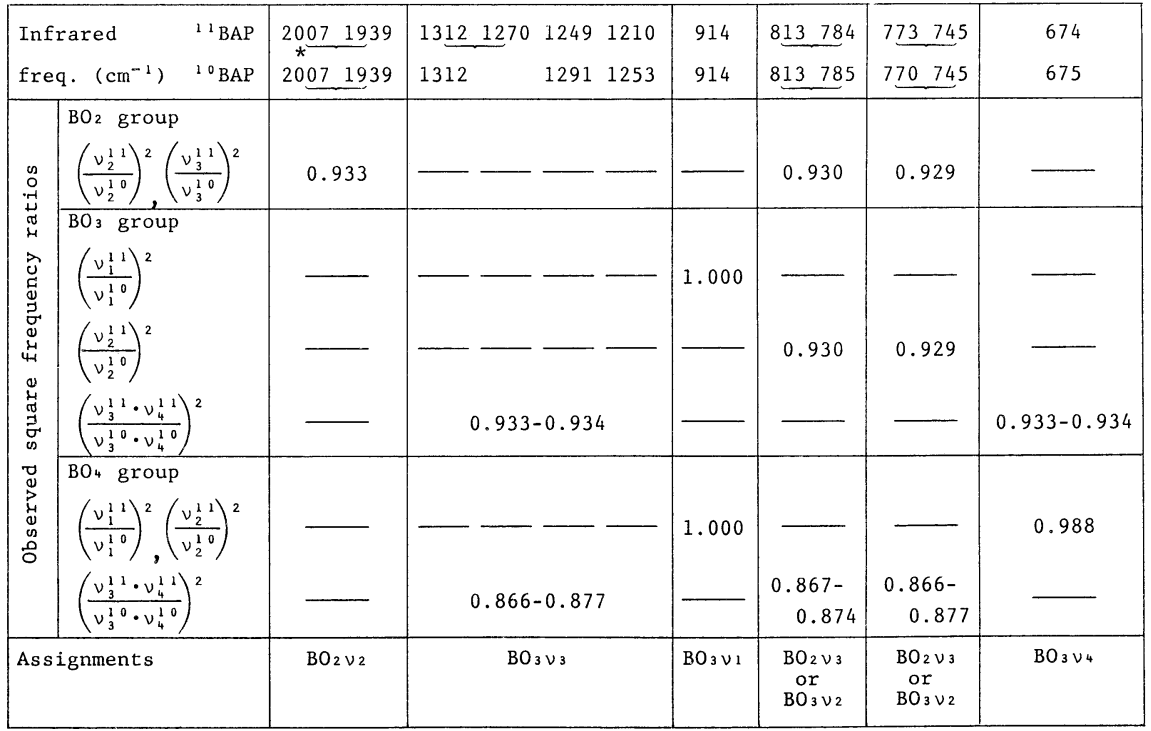




\section{によるものである.}

\section{$3.1 \mathrm{BO}_{2}$ 基の吸収帯について}

$\mathrm{BO}_{2}$ 基は $\mathrm{D}_{\infty \mathrm{n}}$ でも $\mathrm{S}_{6}$ でも，赤外活性な基準振動は二 つ $\left(\nu_{2}\right.$ と $\left.\nu_{3}\right)$ である. 2007 と $1939 \mathrm{~cm}^{-1}$ の同位体ペアは $\mathrm{BO}_{2}$ 基の $\nu_{2}$ であると考えられる ${ }^{2)} . \mathrm{CO}_{2}$ の基準振動 ${ }^{6}$ か ら類推すると $\mathrm{BO}_{2}$ 基の $\nu_{3}$ は $\left(813,784 \mathrm{~cm}^{-1}\right)$ の同位 体ペアか又は $\left(773,745 \mathrm{~cm}^{-1}\right)$ の同位体ペアのうちの いずれか一方であると考えられる. $\mathrm{BO}_{2}$ 基の $\nu_{2} ， \nu_{3}$ に 関して積の法則は表 1 の (1) 式のようになる.ただし $\nu_{\mathrm{k}}^{i}$ は $\nu_{\mathrm{k}}$ 振動モードの振動数で, $i$ は同位体核種を表す. $m(A)$ は分子 (又は原子) $A$ の式量である. 波数の実 測值から (1) 式の左辺を計算すると(表 2, $\mathrm{BO}_{2}$ の欄), 右辺の值と一致した。 $\left(2007,1939 \mathrm{~cm}^{-1}\right)$ の同位体ペア は $\mathrm{BO}_{2}$ 基の $\nu_{2}$ である. $\left(813,784 \mathrm{~cm}^{-1}\right)$ 又は $(773$, $\left.745 \mathrm{~cm}^{-1}\right)$ の同位体ペアのうち一方は $\mathrm{BO}_{2}$ 基の $\nu_{3}$ であ る.

\section{$3.2 \mathrm{BO}_{2}$ 基以外のホウ酸基の吸収帯について}

$\mathrm{BO}_{3}^{3-}$ のグループ振動数は $1280 \sim 1250\left(\nu_{3}\right), 940\left(\nu_{1}\right)$, 800 730 $\left(\boldsymbol{\nu}_{2}\right), 670 \sim 600\left(\boldsymbol{\nu}_{4}\right) \mathrm{cm}^{-1}$ と報告されている7). そこで 1312〜1210，914，675〜674 $\mathrm{cm}^{-1}$ の吸収帯を $\mathrm{BO}_{3}$ 基の $\nu_{3}, \nu_{1}, \nu_{4}$ に帰属し, $\left(813,784 \mathrm{~cm}^{-1}\right)$ 又は $(773$, $\left.745 \mathrm{~cm}^{-1}\right)$ の同位体ペアのうちいずれか一方を $\mathrm{BO}_{3}$ 基 の $\nu_{2}$ に帰属する. $\mathrm{BO}_{3}$ 基が正三角形 $\left(\mathrm{D}_{3 \mathrm{~h}}\right)$ の対称性を もつとすると積の法則は表 1 の (2)，（3），(4) 式のよ うになる. 各式の左辺を波数の実測值から計算すると (表 $2, \mathrm{BO}_{3}$ の欄), 右辺の值と一致した.

次にこれらの $\mathrm{BO}_{2}$ 基以外の吸収帯や同位体ぺアをそ れぞれ $\mathrm{BO}_{4}$ 基の $\nu_{3}, \nu_{1}, \nu_{2}, \nu_{4}$ に帰属することを考える. $\mathrm{BO}_{4}$ 基が正四面体（ $\mathrm{T}_{\mathrm{d}}$ ）の対称性をもつとすれば，積

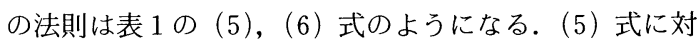
しては実測值と一致したが，(6) 式に対しては一致しな かった (表 $2, \mathrm{BO}_{4}$ の欄). 以上の結果は $\mathrm{BO}_{2}$ 基以外の ホウ酸基が $\mathrm{BO}_{4}$ 基ではなく $\mathrm{BO}_{3}$ 基であることを示して いる. 最終的な吸収帯の帰属を表 2 の最下欄に示す.

\section{4. 考 察}

伊藤ら ${ }^{3)}$ は BAP 単結晶の化学分析と結晶構造解析を 行った. 化学分析から BAP の組成が $\mathrm{Ca}_{10}\left(\mathrm{PO}_{4}\right)_{5} \mathrm{BO}_{4}$ -
$\mathrm{Ca}_{9.5}\left(\mathrm{PO}_{4}\right)_{6} \mathrm{BO}_{2}$ 系固溶体として表せること, すなわち ホウ酸基が $\mathrm{PO}_{4}$ 基と $\mathrm{OH}$ 基の両方を置換していること が示された ${ }^{3)}$. 結晶構造解析からは $\mathrm{B}$ が $\mathrm{OH}$ カラム中 $(0$ $01 / 2$ ）に存在し， 2 個の $\mathrm{O}$ (水酸アパタイトの $\mathrm{OH}$ 基 の $\mathrm{O}$ に相当）に直線的に配位されて $\mathrm{BO}_{2}$ 基を形成して いることが示された ${ }^{3)}$. 本研究では, BAP に $\mathrm{OH}$ 基が 存在しないこと, $\mathrm{BO}_{2}$ 基と $\mathrm{BO}_{3}$ 基が存在すること, 及 び $\mathrm{BO}_{4}$ 基は存在しないことがわかった。このことから $\mathrm{PO}_{4}$ 基を置換したホウ酸基は, $\mathrm{BO}_{4}$ 基ではなく $\mathrm{BO}_{3}$ 基 であると考えられる. $\mathrm{BO}_{3}$ 基がビのような形態で四面 体の $\mathrm{PO}_{4}$ 基を置換するのかはわからない.

端成分 $\mathrm{Ca}_{10}\left(\mathrm{PO}_{4}\right)_{5} \mathrm{BO}_{4}$ は $\mathrm{BO}_{4}$ 基が $\mathrm{PO}_{4}$ 基を置換し, $\mathrm{OH}$ カラムが空孔になっていると従来考えられていた。 しかし,この化合物は $\mathrm{BO}_{3}$ 基が $\mathrm{PO}_{4}$ 基を置換し, $\mathrm{OH}$ カラムに $\mathrm{O}^{2-}$ が存在し, 構造式 $\mathrm{Ca}_{10}\left\{\left(\mathrm{PO}_{4}\right)_{5} \mathrm{BO}_{3}\right\} \mathrm{O}$ で 表せると考えられる.

$\mathrm{BAP}$ は $\mathrm{OH}$ カラムに $\mathrm{BO}_{2}$ 基が, $\mathrm{PO}_{4}$ サイトに $\mathrm{BO}_{3}$ 基が存在し, モル比 $x=\mathrm{Ca}_{10}\left\{\left(\mathrm{PO}_{4}\right)_{5} \mathrm{BO}_{3}\right\} \mathrm{O} /\left(\mathrm{Ca}_{10}\right\}$ $\left.\left.\left(\mathrm{PO}_{4}\right)_{5} \mathrm{BO}_{3}\right\} \mathrm{O}+\mathrm{Ca}_{9.5}\left(\mathrm{PO}_{4}\right)_{6} \mathrm{BO}_{2}\right)$ を用いて一般式

$$
\mathrm{Ca}_{9.5+0.5 x}\left\{\left(\mathrm{PO}_{4}\right)_{6-x}\left(\mathrm{BO}_{3}\right)_{x}\right\}\left\{\left(\mathrm{BO}_{2}\right)_{1-x} \mathrm{O}_{x}\right\}
$$

で表せる.

謝辞 実験に当たり種々御教示頂いた早稲田大学教育学 部地学教室の中村忠晴教授に深く感謝致します.また実験に御 協力頂いた同教室の磯崎哲夫氏に感謝します.

\section{文 献}

1) P. Ramamoorthy and T. J. Rockett, J.Am. Ceram. Soc., 57, 501-02 (1974).

2) C. Calvo and R. Faggiani, J.C.S.Chem. Comm., 714-15 (1974).

3）伊藤敦夫, 青木秀希, 赤尾 勝, 三浦直樹, 大塚良平, 堤 貞夫, セラミックス論文誌，96，305-09 (1988).

4）日本化学会編, “化学便覽改訂 2 版, 基礎編 I”, 丸善 (1975) p. 28.

5) G. Herzberg, "Infrared and Raman Spectra of Polyatomic Molecules", Van Nostrand, Princeton, N. J. (1964) p. 235 .

6）水島三一郎, 島内武彦, “赤外線吸収とラマン効果”, 共 立出版 (1958) p. 155 .

7）島内武彦, 益子洋一郎, 中西香爾編, “赤外線吸収スペク トルー理論と応用一”, 化学の領域増刊 54 号, 南江堂 (1963) p. 112. 